\title{
How Little Cataloging Can Be Effective?*
}

\author{
Mr. Wright is librarian, Williams \\ College.
}

$\mathrm{T}$ HE TITLE of this talk is, I realize, quite indefinite, since there is no general agreement between administrators, reference librarians and catalogers as to the correct measurement of the effectiveness of a cata$\log$. I am assuming that we here are interested in the catalog for a college library, with free access to the stacks, where the catalog is regarded as primarily a finding list of the collections. Although I would not wish to deny the usefulness of the catalog as a reference tool, I do not regard this as its primary purpose. The fundamental purpose of the catalog I am discussing is to show whether the library has a designated book, what works by a given author or on a given subject are in the library, and where these volumes are located.

Now these are not difficult things to record. There have been librarians who have managed libraries running to tens of thousands of volumes by the simple process of remembering these details about all the books in their care. Unfortunately the human memory is not immortal, and it would be unfortunate if the living catalog decided to take a position in some other city. Hence we rely on catalogs to preserve the information needed for each book.

But before considering the catalog and the cataloging process, we might look for a moment at some related activities which may be taking up time, effort and money

\footnotetext{
* Paper presented at a meeting of the College Libraries Section, ACRL, Chicago, February 3, I954.
}

in getting our books into the hands of those who want them. The accession book has been rather generally given up but the transfer of the information about source and price to the book itself or to the shelf list is still frequent. The information is little needed and on the rare occasions when it is wanted the bookplate will usually tell whether the volume is a gift or a purchase and the trade bibliographies will give the original retail price. The marks of ownership need not be extensively duplicated. If a bookplate is used there is no great need of perforating, embossing or stamping the library's name on the book itself. The mislaid book will come home with a single guide and the deliberate thief can remove any marking. Order routines must be watched to make sure that all routines and records are really necessary. Not many of us have enough outstanding orders at any one time so we really need a file of orders by department or fund in addition to an alphabetic file, and of the two the latter is far easier to use. It is usually necessary to record the amounts spent by each department, but if there are only two or three hundred outstanding orders at one time the departmental orders can be sorted out (by use of edge-punched cards if necessary) more cheaply than the extra files can be maintained.

In the detail of cataloging itself a large degree of simplification is possible. If $\mathrm{Li}$ brary of Congress or Wilson cards are used, they should be used as far as possible without alteration, and any cards made locally must be sufficiently consistent with those 
purchased so that the two varieties will interfile. If all cards are made locally, simplification of entry is quite feasible. Author's dates, except in cases of conflict of name, are of little value to the normal college library. The number of homonymous authors which we will meet in our usual collection is very limited. If we use LC cards, then dates will need to be added to local cards when the same author is cataloged, to avoid questions about filing. If all cards are produced locally the classic authors can frequently be cut to their surname only, with some gain in the use of the catalog by having these authors precede those of the same name who are less known.

I should like at this point, however, to interject a warning against the loose thinking which prescribes the use of "the name as found on the title-page" as a quick and easy method of cutting catalog costs. With the idea behind this expression, that pseudonyms and shortened names are acceptable entries, I do not wish to quarrel. But as long as my catalog shows twenty or thirty "Mark Twain" title-pages, three "Mark Twain (Samuel L. Clemens)" and one "Samuel L. Clemens"; as long as the catalog shows works by Virgil, Vergil, Vergilius, Virgile and Virgilio; as long as Shakespeare appears under a variety of spellings, with and without William, and even without the author's name; I should want a statement of exceptions to the "simplified" rule at least as complex as the exceptions to the present rules.

In regard to the form of personal names some simplification is possible which would not prevent interfiling with previous entries. My own pet example of unnecessary complexity is the exclusion of titles and dates from the brackets used to indicate anonymous works. If the heading is supplied, it is the whole heading which we add, so why does not the entire heading go inside the brackets? And how many of the titles which we still add to names, such as "bp." and "pres. U.S.," really add anything of value to the name itself?

The subject of corporate entries is one which I do not wish to investigate very fully now. I have high hopes that the Division of Cataloging and Classification will shortly undertake a major revision of the rules for corporate entry which will remove a large part of their present complexity. I would like to point out here, however, that in our college libraries, containing 50,000 to 300,000 volumes, we can frequently enter all the publications of a body under the simple name of the body without the addition of subdivisions which may be needed in the university and large reference library. If we have ten or even twenty-five publications of the General Electric Company, it does not seem necessary to worry too much about the particular branch which has issued each one. If the information may have some value in locating an incorrectly quoted title, the name of the department or branch can be included in the title, where it does not require any careful establishing, rather than in the heading, where correctness is of greater importance.

The Library of Congress has already done much to simplify the transcription of the title, although their addition of [Ist ed.] to thousands of cards where "only edition" would be more accurate has added an unnecessary complication. Minimum cataloging might omit the majority of sub-titles and all translator notes, except on cards for those standard authors where a variety of translations may be expected. For the great majority of works, including works of literature, only one translation will ever be made and there is in consequence no great need to specify the translator. Because editors are frequently listed in place of authors, there is need of more liberality in using their names both in the title and as secondary entries. Unless illustrations are a major feature of the work or are of par- 
ticular interest in the library any statement about illustrations may be omitted from the title.

The imprint can be reduced if minimum cataloging is being sought. Successful catalogs have omitted it completely for most fiction. The order of importance in the imprint is date, publisher, place. While the date of publication is of little importance in current books, it becomes more valuable with every passing year. If there is any wide variation the copyright date is more valuable than the date of imprint. With obscure publishers the place of publication may assume more importance than the name of the publisher. An effective catalog can give the date alone, but the second element (either publisher or place) will usually be found worthwhile.

The collation statement is something of a luxury. A minimum collation would indicate only multi-volume sets, and perhaps the pagination of pamphlets of less than 100 pages. Progressive steps in complexity would add all pagination; illustration statement, and finally size which is of value only in searching for a book out of its proper place. The great majority of notes can be dispensed with. Contents notes are frequently useful but need not be indulged in when a set consists of several volumes in chronological order. Series notes for sets classified together which aid in locating material on the shelf, and notes of series which have a very specific point of view or form of presentation, are probably worth while.

Although there is plenty of room for argument on the merits of a dictionary catalog, most of us have and will for some time continue to have catalogs of this type. As a result we must deal with the problem of subject headings. I suppose that the great majority use Library of Congress headings: For the smaller libraries a slight simplification may be possible by omitting some subdivisions. For example, my own catalog has only four titles under "Portuguese language" and each card has a different subdivision. Since we are using LC cards, it might prove more expensive to decide on alterations than to accept the full forms given. But certainly if our cards were typed we would save on such items as these. Since such surveys as have been made indicate that the importance of the subject approach diminishes with the age of the book, many older books might be cataloged without subjects. Since general subjects, such as Economics; U.S.-Pol. \& Govt.; U.S.-Hist., appear to be very little used, probably because the number of cards discourages use of the catalog in favor of browsing in the stack, a reference to the appropriate classification numbers might substitute for a considerable number of subject cards. And amorphous books, without a reasonably clear subject, can be left with the author approach alone. As a general rule, with plenty of exceptions, the more difficult a book is to subject head the less necessary the heading.

Title cards can be used sparingly, with recognition of the fact that reference to a work by its title alone is usually a transient phenomenon. Older books are generally sought for by author. This is particularly true for standard works, where the use of title cards can produce, in the William College Library, twenty-six cards under "Hamlet" where one would perhaps be an unnecessary luxury. (In our defense, I should point out that this proliferation of titles was in response to a request from the English Department that every edition of Shakespeare be analyzed under title.) Titles should be used more liberally for works of corporate authorship than for those of personal authorship, since the main entry for the former is frequently garbled or overlooked.

If one uses Library of Congress cards and Library of Congress classification the cheap- 
est method of classification is a direct following of the assigned class numbers. If the classification followed is D.C., some simplification is possible without increase in cost, or with a saving in typing and lettering which offsets any extra time spent in the classification process. Since we are concerned with libraries with free access to the stacks, we do not need to consider in detail the savings possible through storage in accession order of books classified by size only.

Revision of cataloging and of typing is a luxury if a staff is well trained. With every new member of the staff it is necessary to revise until a reasonable efficiency is reached, but no longer. Not even LC printed cards are entirely free from typographical errors, so we may allow a few to occur in our own typing without feeling the need to be too apologetic. Occasional errors of substance, in classification or headings, will be found in filing or otherwise and corrected at far less expense than is involved in careful revision of every card typed.

Duplicate copies can be added to the shelf list only, or, if the information is needed in t':e catalog, to shelf list and main entry only, without the labor of withdrawing the complete set of cards to add or change information on every card. The use of self-cataloging devices for documents and the use of a vertical file for pamphlet material will cut out a considerable amount of cataloging. Periodicals and similar serials currently received can be recorded as "to date" with information about the latest volume kept in the binding record or central serial record. Some libraries circulate paper-backed books with no catalog record at all, merely keeping the volumes on segregated shelves as they are returned. This idea could be extended to any popular fiction purchased for current interest rather than for use as literature.

Since cataloging complexity and costs rise with the size of the collection one method of keeping these within limits is to have a regular program of weeding the collection. The reduction in size allows simpler classification, easier filing, fewer conflicts in names, and a relief from trying to fit subject headings to the slightly varying connotations that words acquire in a century or two of use.

The topic that was assigned me was "How Little Cataloging Can Be Effective?" I suppose a truthful answer to this would be that cataloging which consisted of the author's surname and a brief title rould be, for some purposes, as effective as the preI948 Library of Congress variety of cataloging. For other purposes cataloging of the sort done in the Gesamtkatalog der Wiegendrucke is not sufficient. The good cataloger recognizes the variety of material and varies the type of cataloging accordingly, not being afraid to cut down from the standard rules when it is possible nor to go beyond them when it is necessary. It might be of help to revise Cutter's presentation of short, medium and full cataloging in a new code, if enough of us are willing to admit that the libraries we supervise are not the equals of Congress, New York and Widener.

One thing that is necessary if our catalogs are to be effective is for us, the administrators, to decide on the purposes that the catalog should serve. The cataloger is the proper person to determine how a given objective can be most cheaply accomplished but it is not within the competence of the cataloger to make the ultimate decisions on what those objectives are. The cataloger knows what can be done, the librarian must decide what should be done. And as long as our purposes are ill-defined and vague, our cataloging will be expensive. Trying to accomplish several things at once, we do none of them efficiently. What effect do you want from your catalog?

(Continued on page I75) 
and social sciences, and showed a sampling of its occupational resources, bibliographies prepared by its members, and topics of research for which students sought reference assistance.

To tie together all these activities, the chief librarian and his executive assistant provided a large master chart showing in detail the administrative organization of the Library. Also featured in the chief librarian's exhibit were the services of organizations affiliated with the Library. Outstanding among these are the Library Associates of Brooklyn College, one of whose many activities is the sponsorship of an annual College-Community award to a deserving student, and the $W$ alt Whitman Foundation of Brooklyn, Inc., whose aim is to microfilm all known manuscripts of the Brooklyn poet.

In the surrounding wall cases, the Periodicals and Documents and Education exhibits demonstrated, in an arresting manner, the richness of the resources of these divisions. Each stressed material distinctive to itself.

The display of the Periodicals and Documents Division consisted of a colorful selection of current scholarly and general magazines, newspapers, indexes, microfilms and reference resources in government documents.

Indeed, the variety of the media comprising the Library prompted the Committee to bring together in a wall case entitled "Library Materials" not only examples of types of information already on display but also additional material such as maps, music scores and manuscripts. To represent the latter the Committee chose the original typescript of Frances Winwar's Farewell the Banner, one of six manuscripts presented to the Brooklyn College Library by this author.

Although each of the divisions promotes good relations with its patrons by striving to give good service, there is at Brooklyn a Special Services Division whose primary purpose is to act as liaison between the Library and its public. The Special Services exhibit, therefore, appropriately illustrated its fourfold function of publicity, exhibits, Library publications and student orientation with examples of awards it has won, handbooks and publications it edits, forms and clippings in regard to its exhibits, slides and problem sheets connected with its Library lectures to Freshmen and pages from its publicity scrap book.

With faculty attention concentrated upon the Library it was thought a good opportunity to highlight the professional literature in the field of librarianship. The Committee chose to display current issues of The $\mathrm{Li}$ brary Quarterly, Library Trends, College and Research Libraries, The Library Journal and The Wilson Library Bulletin and to feature such books as Louis Round Wilson's The Library in College Instruction; Fremont Rider's The Scholar and the Future of the Research Library; Louis Round Wilson's The Practice of Book Selection; Dorothy May Norris's A History of Cataloguing and Cataloguing Methods and Herman H. Fussler's Library Buildings for Library Service. A special case called attention to a sampling of the contributions of the Brooklyn College librarians to this literature.

Thus, for the first time in the young history of Brooklyn College Library, participation in Faculty Day provided a significant opportunity for the staff to summarize visually its resources, multiplicity of services and variety of professional activities. Both faculty and staff learn from the experience.

\section{How Little Cataloging Can Be Effective?}

\section{(Continued from page I7o)}

As I look over this paper I must confess to a sense of frustration. These things have been said so often before. And we are still so far from knowing how our catalogs are actually used, and for what uses they should be constructed. Who uses an author's dates, the notation of size, or a series note, and why? Is this title card ever consulted? Does the frequency of use justify the cost of giving collation? Until we know in fairly exact terms how much cata loging is effective, we really have no basis for discussing how little cataloging can be effective. 